\title{
A UNIDADE DO PARTICULAR E OS AFETOS HUMANOS NA TEORIA BENJAMINIANA DA SOBERANIA
}

\author{
Tereza de Castro Callado ${ }^{1}$
}

\begin{abstract}
Resumo:
Na teoria do conhecimento de Walter Benjamin, o particular se articula com a dimensão da força de sua unidade, quando, em um estado de justaposição com outras singularidades, cede à maneira de uma mônada, à sua capacidade de percepção, para comunicar a si mesmo diante do macrocosmo. Essa concepção epistemológica, que emoldura a tematização política de Benjamin visa às arestas da "consciência esclarecida", precisamente na estrutura da subjetividade moderna. $\mathrm{O}$ apelo à mutualidade e reciprocidade característico da mônada aponta para a exigência de uma tematização política do convívio entre os homens, reelaborada para acolher o diferente no universo democrático dos elementos isolados e heterogêneos da totalidade humana, com vistas à comunidade política vindoura.
\end{abstract}

Palavras-chave: Singular,Mônada,Heterogeneidade,Diferente,Política,Comunidade.

\begin{abstract}
:
In the theory of knowledge of Walter Benjamin, the analysis of the particular articulates with the size of the force of his unit, when in a state of juxtaposition with other singularities, it gives way to a monad, his power of perception, to communicateitself towards the macrocosm. This epistemological conception which frames the political philosophy of Benjamin, aim on the edges of the "enlightened conscience" and precisely on the structure of modern subjectivity. The sense of mutuality and reciprocity characteristic of monads points to a new policy theme of interaction among men elaborated to accept the different, the democratic universe of heterogeneous and isolated from human whole, with a view to the coming political community elements.
\end{abstract}

Keywords: Particular,Monad,Heterogencity,Different,Political,Community

$\underline{\text { Introdução }}$

A constatação de uma validade para o singular, como será realizada aqui, pretende contornar não apenas o viés político da história dos particulares, enquanto se constitui também como um agente autorizado no domínio das ciências que procedem a práxis, e, principalmente, à filosofia política. A dificuldade de tal procedimento- acristalização do particular-émuitas vezes impelida pela avalanche de um universal, no conceito, extraído da média, o que empana sua visualização.Sabe-se que a tradição filosófica sempre privilegiou o universal. Diante da aporia filosófica - oespaço usurpado ao particular -observamos a crítica benjaminiana: "É absurdo ver no universal uma simples média. O universal é a ideia"(BENJAMIN, 1984, p. 57). Para transporo obstáculo da média conceitual Benjamin propõe recriar o método cognitivo das ciências humanas habilitando-as à assimilação das diferenças da realidade, a partir de seus extremos. Tendo por fim reduzir o raio de atuação

\footnotetext{
${ }^{1}$ Tereza de Castro Callado é doutora em Filosofia (USP- 2005) e em Literatura Brasileira (USP-1997). É professora de Filosofia da Universidade Estadual do Ceará e autora de "Walter Benjamin - A Experiência da Origem" (Eduece). Desde 2008, é a Editora responsável pelos Cadernos Walter Benjamin.
} 
desse pseudo universal, a atenção será votada à relação do particular com a ideia, procedimento esse que irá desvelar conceitualmente sua participação na totalidade. Essa interface da reflexão acerca de um saber para a Modernidade exige a mobilização de ideias acerca do topos político adequado à constituição das diferenças enquanto elementos imprescindíveis à totalidade. Para Benjamin é na unidade desse particular -nãoalcançávelpela ciência positiva-quese encontra a verdade. Uma vez que é vetado à filosofia falar em tom de revelação, essa verdade se auto-apresentarána ideia-umrecurso do método para preservar a manifestação da verdade na fragmentação.

\section{$\underline{\text { O singular e a totalidade no processo de fragmentação }}$}

A fragmentação seria um dispositivo para manter incólume, às generalizações conceituais, a unidade do particular, meio à complexidade do todo. Na auto-defesa contra a massificação, ele permanece um particular, e enquanto particular contribui enquanto elemento constituinte da totalidade.É da massa que a política ideológica suga seu poder e não da unidade do particular. Sabemos, por isso, que é na massa que o sistema constrói a dominação. No fragmento extraído do cotidiano e que se reproduz no fragmento linguístico reside o método para a teorização política, ou seja a filosofia política de Benjamin está disposta em toda a sua produção, parecendo muitas vezes sob a aparência de difícil acesso. Isso se deve ao método do desvio (Umweg), que tem por objetivo não limitar a ideia às leis da demonstrabilidade conceitual. Ao contrário, tendo em vista a variabilidade do mundo real seu fim é comprovarque a verdade não pode ser capturada por uma rede de conhecimentos, (cf. BENJAMIN, 1984, p. 50), como se a verdade voasse de fora para dentro. Ao olhar da argumentação discursiva eloquente, como é de praxe em uma defesa teórica, sua aparição é imperceptível, uma vez que a verdade está isenta de intenção.O contrário se dá com o saber, que se confunde com posse (Erkenntnis ist ein Haben) (cf. BENJAMIN, 1978, p. 11), e é apropriado na consciência, "mesmo que se trate de uma consciência transcendental".

A verdade como ser indefinível, não possui nenhuma intencionalidade, o que dificulta o acesso a ela. Sua aparição se dá no inconsciente, de que a obra-de-arte constitui um medium de reflexão. O inconsciente se manifesta em fluxos descontínuos, sem linearidade, portanto em fragmentos. Isso explica por que a verdade de uma determinada época aparece na obra de arte. Ela tem o caráter de uma historiografia inconsciente. Dessa forma a arte possui uma relação com a beleza da verdade, que merece ser conhecida: "nada existe de belo que não

\begin{tabular}{|l|l|l|l|l|}
\hline Q & Donista \\
\hline
\end{tabular}


tenha em seu interior algo que mereça ser sabido.(fest steht, dass ohne Wissenswürdiges im Innern es kein Schönes gibt.)(BENJAMIN, 1978, p. 159).

O Symposium de Platão comprova a sintonia entre verdade e beleza: “... Eros pode testemunhar que a verdade não é desnudamento que aniquila o segredo, mas revelação que lhe faz justiça”. Essa verdade não se submete a uma análise positivista, que procede normalmente sob a coerção dos critérios normativos e sob as leis da demonstração dedutiva e indutiva, negligenciando o aspecto inesgotável da natureza. Sua verdade, ao contrário-àmedida que renuncia a uma linearidade-se deixa brilhar em uma aparição no belo da obra de arte. Dessa forma a elaboração de um pensamento, em Benjamin, acerca da verdade política vai buscar munição para se defender das generalizações, na forma dos ensaios, pequenos tratados, no Konvolut das Passagens, estudos dissertativos, produzidos desde a Metafísica da Juventude à fase da maturidade. Eles deixam transparecer de maneira pulverizada o "enigma" de uma tematização política, que privilegia o singular e a diferença. A dificuldade aparente na conexão de um sentido ao outro se traduz em uma espécie de hermenêutica. Nela permanece velado o verdadeiro objetivo da unidade, ou seja, a desconstrução criteriosa do totalitarismo subjacente, frente ao qual estaria fadado a desaparecer o particular e sua força revolucionária. Vem da singularidade e principalmente da forçade sua unidade a prática de uma política democrática.

Assim, a pigmentação ideológica dos totalitarismosé o alvo dos estilhaços significativos disparados pela iluminação profana do pensamento crítico de Benjamin, que se encontra na conceituação das diferenças constituintes da beleza do todo, apresentadas em forma de elementos isolados e heterogêneos (aus Einzelnem und Disparatem treten sie zusammen). Eles não deixam de manifestar "o impacto transcendente quer da imagem sagrada quer da verdade" (BENJAMIN, 1978, p. 10). O método de exposição em que "o fragmentário tem primado sobre o sistemático" consiste em um recurso para manter garantido o apelo à convivência política necessária, despistando o desvio sectário da época dominada pelo totalitarismo. E tem em vista a tematização da democracia, no front contra o inimigo.Pois, quando a mentalidade burguesa se vê alienada, através das operações do processo de produção (Herstellungsverfahren), ela reproduz igualmente, nas metamorfoses da consciência burguesa, o mesmo processo de repetição, massificando-se a si mesma e ao mundo, apesar de uma aparente constituição para mudanças. O que predomina é o mesmo, movido pelo poder da massa. Dissolve-se a aceitação ao outro, ao diferente. $\mathrm{O}$ apelo à identidade funciona como um talismã. E esse sentimento de identidade no processo de produção não admite a

\begin{tabular}{|l|l|l|l|l|}
\hline Gevista 2 ialectus & Ano 2 & n. 6 & Janeiro - Agosto 2015 & p. 192-203 \\
\hline
\end{tabular}


criatividade, a espontaneidade. O mundo se massifica, neutralizam-se as instâncias vitais em prol do sacrifício ao mesmo. A não-identidade pensada por Adorno funcionaria como uma espécie de resistência ao status quo da massificação. Em Benjamin a atenção voltada ao particular diminui o desgaste provocado pela massificação através da qual o sistema ilude com a ideia falsa de novidade, com a qual manipula a massa desavisada.

Benjamin observa no choque um dispositivo que pode ser canalizado como sinal de alerta. Para se alcançar o conceito "despertar"a partir do particular e de sua unidade, no Ser, é preciso ter em mente as condições abismais da Modernidade, como a pós-história do conflito que Benjamin descobre no trabalho filológico da arte seiscentista, na ânsia em conciliar ordem do mundo com o movimento natural das coisas(cf. CALLADO, 2004, p. 135),em suma, compreender a tensão de um mundo sem referências- uma vez perdido o elo que unia o homem à transcendência, naquele contexto da Reforma- e sobretudo tendo ainda que enfrentar a catástrofe da perda do ethos históricoe, portanto,em uma realidade despojada de garantias e do apoio outrora assegurado pela religião objetiva. Refiro-me ao gesto de desgarrar-se dos condicionamentos em que a espontaneidade do homem, coibida como ato blasfemo contra as leis da abstração conceitual, no segmento estatal absolutista, por exemplo, inseria-se no plano do profano, sob a égide da expropriação dos bens eclesiásticos, onde se dispersa não somente o elemento material.

Toda a relação dessa mentalidade com o anímico se desvincula daquilo concebido anteriormente como sacralidade. É desse fenômeno que Max Weber extrai seu conceito de desencantamento do mundo (Entzauberung der Welt). O sagrado migra para outros segmentos da instituição, para a política, por exemplo. A política passa a preencher o espaço da credibilidade que é negado à religião.Ela se transforma em ideologia, ao assimilar aqueles remanescentes teológicos expatriados pelo novo elemento dominante- a verdade científica, uma vez absolutizada pela "racionalidade" do Século das Luzes. A ciência passa a ter o prestígio do qual a religião gozava em outros tempos- prestígio da Fé. Éjustamente sobre o dogma político- aquié preciso dar realce a essa constatação- dogma esse consolidado em forma de síntese ideológica nos totalitarismos da modernidade- sejam políticos ou filosóficos- que sugerimos dialogar tendo em vista um novo arranjo metodológico para a reflexão,agora incólume a condicionamentos, no dizer de Benjamin, e liberta do preceito doutrinário imperativo (cf. BENJAMIN, 1984, p.50). Ilustro essa ideia com um ensaio de Marramao sobre as gnoses da Modernidade, "reconhecíveis no denominador comum da autodivinização do homem"(MARRAMAO, 1997, p. 95) a partir da evidência do

\begin{tabular}{|c|c|c|c|c|}
\hline Genista Oialeotus & Ano 2 & n. 6 & Janeiro - Agosto 2015 & p. $192-203$ \\
\hline
\end{tabular}


desaparecimento das concepções divinatórias, na mentalidade da estética barroca, ou seja, na realidade do Deus absconsoda ética luterana, e, para agravar ainda mais, justamente quando o objeto de culto é capturado ante o furor ctônico gerido pelo antropocentrismo nascente. Ele se deixa confiscar pela ciência política, quando esta se revolve na própria cintilação, no momento em que passa a ser o expoente da verdade.

Essa concepção sobre o processo de secularização que transforma as coisas de deus em coisas do mundo, já temidas por Santo Agostinho, são referidas por Marramao eacordadasna obra de ErichVögelin(cf. VÖGELIN, 1966, p. 196). Assim persistiria em estudos teóricos da modernidade-complementa Topitsch,referindo-se à doutrina marxiana para a política de seu tempo-“a imanentização hegeliana do sistema triádico da divindade que se torna autoconsciência ao finitizar-se no mundo" (TOPITSCH, 1969[FALTA A PÁGINA!]). Na trilha da mesmapercepção, ou seja, de uma dogmatização derivada da concepção divinatória e migrada para o plano do profano, ou seja, exercitada na política, teríamos na concepção do Gogarten do ensaio KulturundReligion da obra Illusionen, eineAuseinandersetzungmitdemKulturidealismus, original de 1926 (pp. 139-141): o secularismo, fenômeno das "religiões políticas", com sua pretensão de absolutizaro agir humano e de totalização das instituições político-sociais, em outras palavras: “desenraizamento das formas de vida tradicionais".Mais uma vez podemos nos referir à relação-exclusão entre a cidade de Deus e a cidade dos homens. O homem pretende esconder a necessidade do divino com sua autoimagem, agora ela própria divinizada. Doravante ele passará a ter a ilusão de se movimentar bem diante dos percalços, para a solução dos quais se recorria antes à Providência.

Nos tempos modernos, é preciso acrescentar que esse fenômeno foi possibilitado pelo desvio da subjetividade e seu extravasamento, agora de forma canônica e sectária, e tendo em vista os diferentes estratos da política. Concluímos esse tema, apontando ligeiramente, como um dos nódulos, visíveis na investigação da Organização estatal da Modernidade, a secularização. Ela seria outro estágio da sacralização, de que não estão isentos os sistemas políticos aludidos, ou seja, os que atuam ideologicamente, devedores de uma "estrutura mística da autoridade",como já havia preconizado Michel de Montaigne (MONTAIGNE, 1988, p. 141), eem linguagem mais atual, de um "culto da personalidade", de uma "subjetividade inflada," ou ainda, remontando à antiguidade, de um "nomosempsychos", ou lei viva, que,desde os clássicos antigos,o mundo conheceria. Repetimos: a secularização seria outra forma de culto ao sagrado, não mais processada pelo dogma de revelação,mas

\begin{tabular}{|l|l|l|l|l|}
\hline Q & Donista \\
\hline
\end{tabular}


professada na consciência embotada pelo fragor ideológico da salvação irradiado em um processo de redivinização da sociedade como chave que desvela a "intima lógica do desenvolvimento político ocidental”.(VÖGELIN, 1966, p. 196).

Atribui-se ao mesmo fenômeno, o aparecimento de sua contra-moeda: a concepção do capitalismo como religião, na análise benjaminiana das bases ideológicas que sustentam a mentalidade profana atual(BENJAMIN, 1977, p. 100). Trata-se de uma religião puramente de culto, talvez a mais extrema que já houve, que não conhece nenhum dogma especial, nenhuma teologia, e sob a qual o utilitarismo ganha nuanças e matizes religiosos. O capitalismo é o primeiro caso de um culto que nunca dá a chance de expiação, portanto de um culto sempre devedor. Otípico do pensamento sobre a religião capitalista encontra-se, expressivamente, em Nietzsche. Encastoado nele se revelam as variantes das gnoses político-econômicas. Elas arrefeceriam o apelo ao transcendental "tragando o divino para o foro da interioridade". Com isso constrói-se o mito da personalidade da qual a instituição é a forma autorizada. Na medida em que a projeta para além da massa amorfa, esse mito cria derivações como identidade, sujeito, autonomia, terminologias destinadas a empanar a realidade da massificação e do domínio com suas tentativas de homogeneização do mundo. (Vögelin vai chamar a esse ato o de imanentizar o significado da existência).

Também para Benjamin o apelo à imanência inicia-se historicamente ao se experimentar o constrangimento diante de uma transcendência inalcançável, fenômeno que gera a desesperança e o desconsolo, e que leva o homem a espojar-se entre signos, rótulos e emblemas na busca de sentido e diante de uma transitoriedade inalienável. A autoredenção constituiria a chave explicativa da Modernidade da gnose, explica ainda Vögelin. Vögelin compara o apelo a gnose às primeiras imanentizações medievais do eschaton, sendo agora outro o ponto de apoio. Não mais Deus. O próprio homem aparece como signo. Segundo Freud,

se você quiser expulsar a religião de nossa civilização europeia, só poderá fazê-lo através de outro sistema de doutrinas, e esse sistema, desde o início, assumiria todas as características psicológicas da religião - amesma santidade, rigidez e intolerância, a mesma proibição do pensamento - para sua própria defesa(FREUD, 1997, pp. 79-80).

Com essa lógica atuaram e continuam atuando os totalitarismos. O processo de desdivinização do mundo e redivinização, onde o homem pretende assumir o "papel" de Deus, se alastraria pelo "humanismo, progressismo, liberalismo, positivismo. Chegando ao marxismo, com sua

\begin{tabular}{|l|l|l|l|l|}
\hline Gevista 2 ialectus & Ano 2 & n. 6 & Janeiro - Agosto 2015 & p. 192-203 \\
\hline
\end{tabular}


ideia de 'revolução total' constituiria a forma extrema dessa secularização perversa" (MARRAMAO, 1997, p. 96). Também o filósofo austríaco Topitsch, fiel a sua inspiração antidialética,

\begin{abstract}
identifica o centro de irradiação da influência gnóstica sobre as ideologias contemporâneas numa particular forma de pensamento: a do idealismo alemão. Aqui teriam sido refundidos os elementos salvíficos e escatológicos das correntes neoplatônicas, gnóstico-herméticas e cabalistas presentes no contra-iluminismo alemão entre os séculos XVIII e XIX. E deste modo terse-ia difundido a postura mitológica e anticientífica típica de muitas das ideologias utópico-revolucionarias contemporâneas e, acima de todas, do marxismo, que representa para Topitsch a verdadeira e própria gnose da Modernidade(MARRAMAO, 1997, p. 98).
\end{abstract}

Para Benjamin, no processo de igualdade dos socialismos modernos se dá a fratura da unidade do singular e o esvanecimento de sua força para reproduzir a alteridade. $\mathrm{O}$ contraponto a esse status quoé feito de forma monadológica, quando convocada a percepção para o diferente, como já praticaram de forma exemplar direta ou indiretamente os antigos. Cito Etienne de La Boetie, alertando sobre o risco do dogmatismo, com o "Discurso sobre a servidão voluntária”, Jean-Bodin, chamando a atenção para a inexistência de um código único para gerir a coisa pública e mesmo Maquiavel, comseu faro para o princípio antropológico, sobre o qual fundou um raciocínio político consequente.Esses expoentes do pensametno, ao colocarem a habilidade política em uma engrenagem linguística cifrada a orientar o estadista, não foram de todo imunes à rejeição de suas teorias, uma vez que a fundação do código para o comportamento é a mesma da lei positiva. Nela a força para a justiça se esvai na padronização, na medida em que é desconsiderado o valor do singular. Essa redução a um padrão e a um rótulo se origina no mito. Assim nem mesmo o sistema jurídico e a lei positiva escapam de sua derivação no poder mítico.

A experiência do estadista barroco ao abrir o estado de exceção(Ausnahmezustand) político na alma - na forma como é valorizada na cena da dramaturgia barroca comentada por Benjamin- tem outra origem. Ela se baseia na experiência singular, que desperta a interioridade do soberano. Ter a mão um "saber lidar com os fatos" exige um conhecimento de base antropológica, enraizado nas leis da calculabilidade do agir, na lei dos afetos humanos, na criatura, que se dilata na ideia destinada à descrição do humano, enquanto configuração em que um ato extremo do agir se encontra com o outro extremo, entendendo-se sob essa ideia, a gama de conceitos vinculados ao comportamento. A "exceção"doestadista seria a atitude de transformar "a dinâmica da história em uma ação política", diz Benjamin no

\begin{tabular}{|l|l|l|l|l|}
\hline Q & Anista & D. 192-203 \\
\hline
\end{tabular}


Trauerspielbuch, e para a qual é convocada toda a força do conhecimento e da experiência, nos jogos da tradição. Acumular sabertransmitido de uma geração a outra é construir experiência. Recordemos o momento em que a gruta hibernal do absolutismo é iluminada pelo conhecimento da singularidade, quando o monarca se identifica com o menor dos governados pela vivência de uma origem comum, justamente quando "o poder de animalidade e dos afetos, sobretudo o amor e o medo, sua ausência de limites são convocados ao palco da atividade política e confrontados à inteligência e à vontade.” (BENJAMIN, 1984, p. 118). É justamente no conflito entre essas forças, ou esses afetos, que se dá o estado de exceção. E ele acontece de fato, apesar dos entraves que o espírito enfrenta, enredado em outros interesses, e negando toda a tradição do mito cristão, para se revelar enquanto "faculdade de exercer a ditadura", em nome do código legiferante do sistema jurídico do principado barroco. Apesar dessa constatação funesta o estado de exceção se realiza para salvar o outro, fundando ao mesmo tempo uma outra teoria da soberania, na medida em que fratura a soberania absolutista. O estado de exceção é alimentado pela singularidade e força de sua unidade, vinculada à frágil força messiânica, a despeito de toda coerção ideológica exercida sobre as leis naturais da espontaneidade e da boa vontade.

Precisamos reconhecer a necessidade, para a existência em geral, e principalmente para a política, dessa concepção trazida de Kant e atualizá-la. Reconstruindo o pensamento sobre o conceito limite de soberania em Carl Schmitt: "soberano é aquele que decide em um estado de exceção" (Souverän ist, wer über den Ausnahmezustand entscheidet), (SCHMITT, 1996, p. 11) Benjaminmostra que soberano é aquele que, rompendo com as arestas de sua consciência mergulhada no êxtase absolutista, decide em favor do outro, exercitando o verdadeiro estado de exceção na alma, e ele o faz por encontrar em sua singularidade, a mesma unidade do particular,através da qual se identifica com o súdito menor. Essa unidade se encontra na origem de ambos - na experiência de uma origem comum - a condição humana(cf. CALLADO, 2006, p. 27). Relembro aqui e é sempre bom lembrar de novoa tragédia de Antígona, ao auscultar as leis morais do coração. No caso da dramaturgia barroca, essa mesma experiência em dar ouvidos à lei moral, inscrita, não no cânone político, mas na própria dignidade, a mais inusitada, nas contingências políticas do absolutismo, consegue fraturar o poder, invalidando a normatividade do Direito Constitucional, que transfere, equivocamente, para o rei, as insígnias da origem adâmica, particularmente defendidas por Robert Filmer, em $O$ Patriarca.Sustando toda essa avalanche mítica, o estado de exceção político antevisto na camada metafísica da dramaturgia barroca, se torna possível no apelo à

\begin{tabular}{|l|l|l|l|l|}
\hline Gevista Dialectus & Ano 2 & n. 6 & Janeiro - Agosto 2015 & p. 192-203 \\
\hline
\end{tabular}


singularidade do estadista, e não na celebração de sua subjetividade, através do culto à personalidade estatal.

A exceção esgarça a subjetividade, em nome do particular. Como em Jacques Derrida essa desconstrução política constitui a justiça.Há muito ela exilou-se da consciência da Modernidade, para esconder-se no inconsciente. E é diante do embotamento da consciência pelo narcótico ideológico que a percepção de Benjamin alcança o desenrolar das metamorfoses da consciência burguesa como um grito último de libertação que fica inaudível. Ao contrário do que conjecturava a tradição acerca do coletivo, verifica-se nele o esmagamento da espontaneidade, enquanto a força propulsora da verdade, na criatura, emana do particular monadológico. São as diferenças em justaposição, a representação cabível do real. Ela não dispensa o outro. Supõe entrecruzamentos recebendo de cada unidade a qualificação para medir a dinâmica das interações. A maneira da mutualidade e da reciprocidade visíveis em uma mônada, contraria o senso comum na base em que é pensado o coletivo para o momento positivista. O singular, seja ele na sua diferença, revolve a generalização conceitual que assedia o pensamento, e na medida em que acena para a perda do senso crítico perante a expansão da subjetividade, tenta recuperá-lo do ilogismo, na expressão da experiência (Erfahrung).

Nesse sentido subjetividade e singularidade são conceitos excludentes. Se a subjetividade cria pelo desejo, a tenacidade do singular destrói a subjetividade para poder criar. A força do singular encontra-se na experiência transmitida entre as gerações. Ela forma uma cadeia de saberes, recolhidos pela memória. Nas comunidades orgânicas da tradição a figura do narrador representa um modelo da particularidade atuando com a força de sua unidade.Ao recepcionar a tradição, cada nova singularidade a recria, acrescentando aos bens culturais o seu quinhão de conhecimento, para a criação de uma outra comunidade. Esse recolhimento vai gerando a competência. Estruturada sobre ela vem a autoridade natural que consiste num saber de fato, não de posse(ErkenntnisisteinHaben)(BENJAMIN, 1984, p. 51). A ausência da sabedoria gera o autoritarismo, e seu fundamento vazio, apoiado na linguagem com sua retórica, no discurso grandiloquente da propaganda, "tagarelice" pura no dizer de Benjamin, somente capaz de convencer a massa, mas não o singular com sua unidade, uma vez que a lógica arbitrária do coletivoparte deum código, mera convenção ou sinal emblemático, não mais capaz de dar conta das sutilezas linguísticas, na expressão política da democracia.

\begin{tabular}{|l|l|l|l|l|}
\hline Gevista Qialectus & Ano 2 & n. 6 & Janeiro - Agosto 2015 & p. 192-203 \\
\hline
\end{tabular}




\section{Considerações Finais}

Concluímos que o pensamento deve ser capaz de reelaborar o que, a partir do solo material da história, foi edificado, e nessa mudança de paradigmas, refletir significa fazer uma “imersão no pormenor do conteúdo material”, aconselha Benjamin, pois o pensamento suporte de abstrações lógicas, no conceito, enredado na evidência cartesiana, adquirida na cadeia de razões, declina na sua capacidade de conceituar o "fenômeno da modernidade", caracterizado pela indefinição.

A situação se agrava quando a definição arbitrária do conceito recorre à palavracomo meio (Mittel), e a linguagem perde a comunicação do concreto para o abstrato, a partir da queda,quando o homem já não tem o poder de comunicar com a linguagem nomeadora. Para Benjamin o movimento surrealista, "último instantâneo da inteligência europeia" foi o mais apropriado a auscultar o abalo da linguagem, esculpida para a comunicação em seus desregramentos. Cai juntamente com ela o $\mathrm{Eu}$ concebido isoladamente, ou seja a subjetividade, dando lugar à expressão do inconsciente. O Surrealismo - movimentotanto político como estético -cede à verdade do singular no inconsciente. Ele percebe o abalo da subjetividade, através do êxtase, elemento revolucionário, expatriado da racionalidade e que retorna como recalque. Constituindo o elemento propulsor da crítica, no ato revolucionário, ele eclode fetichizado e em forma de subjetividade, de dentro do coletivo. Torna-se um empecilho na referência àverdadeira revolução contra as forças arcaicas do mito: a revolução disciplinada do singular, que se faz no inconsciente. O conceito de coletivo nutrido na consciência gera uma babel de interesses disfarçados anuviando a verdadeira válvula propulsora que imerge das singularidades contra a estagnação do mesmo.

Falemos agora do antídoto da estagnação e do conformismo: a força da experiência, aquela capaz de recolher o conhecimento da história e transformá-lo em ação política na medida em que prepara o estadista para tomar a decisão (Entschlussfähigkeit). Não são os sistemas políticos responsáveispelo desajuste e desfaçatez e sim a inexistência do singular com sua unidade. Ele é imune às uniformizações levadas avante pela dominação. Contraponto no inconsciente, cuja força Benjamin descobre no surrealismo, alcançamos a denúncia à padronização que rechaça a força do singular e seu impulso em atingir a completude no outro.

Agamben encontra na singularidade a base para uma outra comunidade, "a comunidade que vem". Ela não irá renunciar a um qualquer, conceito positivo, liberto de titulações, rótulos canônicos, emblemas. Tomás de Aquino designou-o quodlibet. Na

\begin{tabular}{|l|l|l|l|l|}
\hline Genista Dialectus & Ano 2 & n. 6 & Janeiro - Agosto 2015 & p. 192-203 \\
\hline
\end{tabular}


Tereza de Castro Callado

enumeração escolástica dos transcendentais, precisamente na Suma Teológica de Aquino,qualquer ente que se queira é "uno, verdadeiro, bom ou perfeito" (quodlibetens est unum, verum, bonum, seu perfectum) (AGAMBEN, 2013, p. 11). Pois o amor, diz Agamben, "não se dirige jamais a esta ou aquela propriedade do amado" -ser pequeno ou negro ou cristão (AGAMBEN, 2013, p. 11),mas tampouco prescinde dela em nome da insípida generalidade. O ser feliz, de posse de seus predicados e podendo fazer uso deles é íntegro (Aqui abro um parêntese para lembrar Benjamin aludindo à felicidade do homem antigo, amparado pela sua vida plena). Continuo com Agamben, para quem "ele (o amor) quer o ser com todos os seus predicados, o seu ser tal qual é”. Ele deseja“o qual(quodlibet)somente enquanto é tal" - com os seus predicados - e esta singularidade é a sua particular magia.

\section{Referências Bibliográficas}

AGAMBEN, Giorgio, A comunidade que vem, tradução de Cláudio Oliveira, Belo Horizonte: Autêntica Editora, 2013.

BENJAMIN, Walter. Ursprung des deutschenTrauerspiels, Frankfurt am Main: 202 SuhrkampVerlag, 1997.

São Paulo: Brasiliense, 1984.

Origem do drama barroco alemão, tradução de Sérgio Paulo Rouanet, "Kapitalismus als Religion" in:__ Gesammelte Schriften, Band VI,

Frankfurt am Main: Suhrkamp Verlag, 1977.

BURTON, Robert, A anatomia da melancolia, Tradução de Guilherme Contijo Flores, Curitiba: Editora UFPR, 2011.

CALlADO, Tereza de Castro, "O drama da alegoria no século XVII barroco" in:_Kalagatos, Fortaleza: Eduece, 2004.

CALLADO, Tereza de Castro.Walter Benjamin - A Experiência da Origem, Fortaleza: Eduece, 2006.

DERRIDA, Jacques, Torres de Babel, Tradução de Junia Barreto, Belo Horizonte: Editora UFMG, 2002.

DIDI-HUBERMAN, George, Sobrevivência dos vagalumes, Tradução de Vera Casa Nova, Márcia Arbex, Belo Horizonte: Editora UFMG, 2011.

ESPINNOSA, Baruch de, Tratado Teológico-Político, Tradução de Diogo Pires Aurélio, São Paulo: Martins Fontes, 2003.

\begin{tabular}{|c|c|c|c|c|}
\hline Rovista Dialectus & Ano 2 & n. 6 & Janeiro - Agosto 2015 & p. $192-203$ \\
\hline
\end{tabular}


Os Pensadores, São Paulo: Victor Civita, 1983.

FREUD, O futuro de uma ilusão, Tradução de José Octávio de Aguiar Abreu, Rio de Janeiro: Imago, 1997.

MARRAMAO, Giacomo, Céu e Terra, tradução de Guilherme Alberto Gomez de Andrade, Fundação Editora da UNESP, 1997.

MONTAIGNE, Michel de, "Ensaios III" in:_Os Pensadores, São Paulo: Nova Cultural, 1988.

SCHMITT, Carl. Politische Theologie, Berlin: Duncker \& Humblot, 1996.

SCHLEGEL, Friedrich, O dialeto dos fragmentos, Tradução de Márcio Suzuki, São Paulo: Editora IluminurasLtda, 1997.

TOPITSCH, "Marxismus und Gnosis" in:_Sozialphilosophie zwischen Mythos und Wissenschaft, Neuwied: Berlin, 1969.

VÖGELIN, Anamnesis zur Theorie der Geschichte und Politlik, München, 1966.

WEIL, Simone, Opressão e liberdade, tradução de Ilka Stern Cohen, São Paulo, Bauru: Editora da Universidade do Sagrado Coração - EDUSC, 2001.

\begin{tabular}{|l|l|l|l|l|}
\hline Revista 2 ialectus & Ano 2 & n. 6 & Janeiro - Agosto 2015 & p. 192-203 \\
\hline
\end{tabular}

